\title{
JAIME II Y LA CRUZADA DE ALMERÍA
}

\author{
Mª Desamparados MARTÍNEZ SAN PEDRO \\ Universidad de Almería
}

\section{EL SITIO DE ALMERÍA SEGÚN LAS CRÓNICAS}

En la segunda mitad de 1309 Jaime II puso sitio a la ciudad de Almería. Las crónicas castellanas y aragonesas contemporáneas de los hechos suelen ser muy concisas dando breves noticias de la preparación del asedio y de su fracaso. Así, la Crónica General de España de 1344 se limita a decir: «E el rey de Castilla fué cercar Algeciras e don Jayme cercó Almería e toviéronlas así cercadas grant tiempo e non plugo a Dios que las tomasen e tornaron cada uno para sus tierras"'. Igual de breve es la Crónica de Alfonso XI: «E en el tienpo de este rey Mahomad, fué el rey don Fernando a çercar a Algezira e tovola çercada siete meses, y en este tienpo el rey don Jaime de Aragón tenía çercada a Almería. E estos reyes de Castilla e Aragón no tomaron ningunos lugares de aquellos que tenían çercados $»^{2}$. Por su parte, la Crónica Barcinonense relata: «En la fiesta de Santa María de Agosto, año mil trescientos ocho, fué cercada la ciudad de Almería por el señor rey Jacobo y en el mes de enero siguiente se retiro ${ }^{3}$. Como vemos, adelanta en un año los acontecimientos. En la Historia Pinatensis se dice: «Así pues el rey Jacobo, habiendo aparejado una gran armada, asedió estrechamente por mar y tierra la ciudad de Almería, llevando consigo a su mujer Blanca»"

El catalán Ramón Muntaner dedica al suceso mayor atención que los anteriores. Militar y cronista, no asistió al asedio por hallarse en esas fechas en el Mediterráneo

1 Crónica General de España de 1344, preparada por Diego Catalán y $\mathrm{M}^{\mathrm{a}}$ Soledad de Andrés. Madrid, 1970, p. 324.

2 Gran Crónica de Alfonso XI, preparada por Diego Catalán. Madrid, 1976. Cap. LXVIII, p. 405.

3 Chronicon Barcinonense. Marca Hispánica, 1688, p. 758.

4 Vetus Pinntensis Historia Regum Aragoniae. Ad. de 1876, cap. 38, p. 369. 
oriental con los almogábares de Roger de Flor, pero para escribir su obra debió contar con testimonios directos, puesto que la comenzó en 1325, quince años después del asedio. En uno de sus pasajes comenta que «... el rey de Castilla fue con todo su poder a sitiar Altzehira de Alhadra, y el señor Don Jaime de Aragón la ciudad de Almería que es una ciudad muy importante. $Y$ el sitio, que duró mas de nueve meses, lo mantuvo el señor rey de Aragón con trabucos y manganos y con todos los artefactos adecuados para mantener un sitio, pues el señor rey de Aragón fué allí muy bien pertrechado, con muchos ricoshombres y barones de Cataluña y Aragón. Entre otros, vino con él el infante Don Fernando de Mallorca, muy ricamente pertrechado, con cien caballos armados y muchos hombres de a pie y con galeras y con leños que traían los caballos y víveres y compañías y trabucos, pues el rey de Mallorca quiso que viniera en ayuda del señor rey de Aragón bien equipado de todo, como pertenecía a quien era, uno de los mejores caballeros del mundo. $Y$ asi lo demostró en todos los lances en que tuvo que intervenir durante el sitio, pues entre otros hechos tuvo por tres veces que enfrentarse con los moros y de todo el mundo tuvo que ser loada la caballería del infante don Fernando» ${ }^{5}$.

A pesar de toda esta preparación la toma de Almería no llegó a buen fin por la deslealtad del rey castellano que lo abandonó a su suerte. Bien es verdad que los aragoneses lograron la victoria de San Bartolomé, pues sigue diciendo Muntaner que «... todo el poder de Granada cayó sobre la hueste del rey de Aragón que mucho se sorprendió, pero lejos de desmayar, ordenó al señor infante Don Fernando que estuviera con su compañía cerca de la ciudad de Almería, para que nadie saliera de la ciudad, y que si alguien salía, atacase el sitio mientras ellos combatían a los sarracenos y el señor infante mantendría la defensa ${ }^{6}$. El rey atacó a los moros y los derrotó celebrándolo al día siguiente, fiesta de San Bartolomé, apóstol.

Cuando el rey de Granada vió la maravilla que el rey de Aragón y los suyos habián logrado, se dio por perdido y envió unos mensajeros al rey aragonés rogándole que levantara el sitio por tres razones: la primera, porque el invierno se venía encima; la segunda, porque no encontraría ayuda pues los castellanos habían abandonado para que él y sus gentes se perdieran, y la tercera e importante, porque le prometía ser en todo tiempo y lugar su aliado contra todos los hombres del mundo y que en su honor libertaría a todos los cautivos cristianos que sumaban un gran número y que era algo más importante que si hubiera tomado dos ciudades de Almería. El rey Don Jaime reflexionó la cuestión, firmó la tregua y mandó embarcar a toda su gente con sus pertenencias de regreso al reino de Valencia ${ }^{7}$.

Jerónimo Zurita, en el Libro $V$ de sus "Anales del Reyno", describe también la gesta de Jaime II en Almería, relato que posteriormente recogerá Orbaneja, y dicen: «... movió Dios el espíritu valiente y el corazón animoso del rey de Aragón don Jayme

5 MUNTANER, R., Crónica. Madrid, 1970, cap. 246, p. 505.

6 Ibídem, cap. 247, p. 506.

7 Ibídem, cap. 247, pp. 508-509. 
el Segundo y aviendo convocado gran número de cavalleros valencianos, catalanes y aragoneses juntó un grande y copioso exercito.

Procuró antes con el abad de San Juan de la Peña que le diese un braço o alguna reliquia del cuerpo del gran Prelado y Apostol San Indalecio, obispo que fué de la primitiva iglesia de la ciudad de Urci, de cuyas ruinas se fundó Almería, por la gran devoción que tenía hacia el glorioso santo discipulo de Santiago.

Con tan preciosa reliquia y resguardo embarcose el Rey en la playa de la Ciudad de Valencia a 18 de el mes de Julio, hizose a la vela y llegó a el Puerto de el Cabo de Aljud donde se avía de juntar toda la armada. Detuvose el Rey en aquel puerto hasta primero de agosto, donde ordenó su exercito, para ir sobre la ciudad, así por mar como por tierra, lo qual tenía consultado con el Rey de Castilla».

Y continúan diciendo: «... partió el Rey de Cabo de Aljud con su exercito por tierra, acompañado de la Reyna Doña Blanca su mujer y de grandisima nobleza; pusose sobre la ciudad de Almería a 15 de el mes de Agosto, día de la Assumpción de Nuestra Señora; dispusose el campo con grandes prevenciones militares, de máquinas, trabucos, de batería y muchas torres de madera, que se avían labrado solo para este fin; comenzaron a hacer algunas minas y pusieron la Ciudad en gran estrecho combatiendola por mar y por tierra.... ${ }^{8}$.

El cerco duró cuatro meses y el 19 de Diciembre el rey de Granada presentaba al de Aragón sus credenciales prometiéndole que si levantaba el cerco pondría en libertad a todos los cautivos y además sería un amigo fiel permitiendo a todos sus vasallos que tratasen y comerciasen con los aragoneses.

Jaime II consideró estos beneficios y consultando a los grandes del Reyno decidió, el 26 de Enero de 1310, levantar el cerco y volver con su ejército a Alicante desde donde pasó a Valencia.

\section{PREPARACIÓN DEL ASEDIO}

En 1308 Jaime II concertó con Fernando IV de Castilla una entrevista, para la que propuso como lugar de reunión "las partidas de Valencia», tierra con mejor caserío y menos fría que la castellana. Pero hubo de aceptar la opinión de don Fernando, que señaló Ariza, en tierras sorianas, vecinas de las aragonesas ${ }^{9}$, para pasar luego al monasterio de Santa María de Huerta.

Procedieron primero a consolidar los lazos de amistad y la paz firmada cuatro años antes en Agreda en la que hubo reparto de tierras, para tratar después la empresa granadina, llegando a las siguientes conclusiones:

8 ZURITA, G., Anales de la Cronica de la Corona de Aragón. Anotado por A. Ubieto Arteta. Valencia, 1967. Lib. V, caps. 78 al 84. PASCUAL Y ORBANEJA, G., Historia de Almería en su antigüedad, origen y grandeza. Ed. facsímil. Almería, 1975, pp. 89-92.

9 JIMÉNEZ SOLER, A., Don Juan Manuel. Zaragoza, 1932, p. 38. 
1. Hacer la guerra por tierra y por mar contra el reino nazarita, hasta su total destrucción. Empezarían en el mes de junio del año siguiente a partir del día de San Juan. Castilla cercaría Algeciras y Gibraltar, y Jaime Il la ciudad de Almería.

2. Como esta conquista pertenecía a Castilla por anteriores tratados entre ambos reinos, Fernando IV cedía a Jaime II, por su participación en la empresa, la sexta parte de las tierras situadas en la zona oriental del reino de Granada, que venían a constituir la zona de Almería, y, si ésta no llegase a tanto, se comprometía a completar dicha sexta parte con otros lugares del reino, a juicio y determinación del arzobispo de Toledo y del obispo de Valencia, y, si valiese más, la sobra, a juicio de los referidos prelados, quedaría para el rey de Castilla.

3. Nunca se haría la paz y tregua con los moros sin consentimiento mutuo y de los principes don Juan y don Pedro ${ }^{10}$.

Para asentar en firme esta concordia se firmaría posteriormente el Tratado de Alcalá de Henares.

Este tratado ponía las bases para la consecución de los objetivos prioritarios de ambos monarcas. Para el castellano era importante el dominio del estrecho de cara a finalizar la reconquista. Para el aragonés el conseguir Almería suponía, de alguna forma, satisfacer sus deseos imperialistas en el Mediterráneo ${ }^{11}$, ya que realmente esta empresa era como un complemento de sus actividades mediterráneas que se orientaban hacia los países islámicos. Hacía ya mucho que el rey de Túnez era tributario del soberano de Aragón; desde 1290 Jaime II, tras un pacto solemne, era protector de los cristianos residentes en Egipto, y, viudo de Blanca de Anjou, volvió a casarse en segundas nupcias con María de Lusignan, presunta heredera del título de Jerusalén. Almería era, pues, solamente el final de una extensa línea que tocaba los dos extremos del Mediterráneo ${ }^{12}$.

\section{INTENTOS DE JAIME II PARA CONSEGUIR LA BULA DE CRUZADA PARA ALMERÍA}

Si importantes eran las relaciones diplomáticas, no lo eran menos las gestiones económicas que era necesario llevar a cabo para recabar fondos y recoger subsidios para la empresa granadina.

El 12 de agosto de 1308 se había convocado, mediante una bula pontificia de Clemente V, el Concilio de Vienne, para tratar los temas de la reconquista de Tierra San-

10 TORRES DELGADO, C., El antiguo reino nazari de Granada (1232-1340). Granada, 1974. pp. 234-235.

11 HILLGARTH en su estudio El problema del imperio catalano-aragonés, considera que hablar de imperialismo en los siglos XIII y XIV puede ser una declaración ciertamente arrogante. Más bien hubo unos determinados proyectos para una limitada hegemonía en el Mediterráneo occidental. Actas del I Congreso Internacional de Historia Mediterránea, 1980, p. 157.

12 SuÁREZ FERNÁNDEZ, L., Historia de España. Edad Media. Madrid, 1970, p. 355. 
ta, la reforma de la Iglesia y el proceso de los Templarios ${ }^{13}$. Jaime II, sospechando que todo el apoyo de la Iglesia se encaminaría hacia la Cruzada de Oriente, inicia un plan estratégico en torno al Pontificado, para atraer la atención del papa hacia su campaña. En marzo de 1309 envía una embajada a Clemente $V$, que se encontraba en Montpellier, al haber sido trasladada la corte pontificia a Avignon, integrada por Ponce, obispo de Lérida, y Bernardo de Fenollar. Su misión era solicitar, además de otras peticiones, el apoyo económico concretado en que la décima concedida para Cerdeña se aplicase a la proyectada empresa granadina ${ }^{14}$. Esto se consiguió fácilmente y los emisarios escriben desde Mondragón comunicando que la embajada había sido positiva:

«... la primera peticio que otorga, que la décima que era ainstada per lo viatge de Cerdenya sia mesa e liurada a vos por lo viatge de Granada» ${ }^{15}$.

Efectivamente, por un breve de 19 de Marzo, el Papa ordena al obispo de Valencia y al abad del Monasterio Fixense, colectores de las décimas eclesiásticas en el reino de Aragón, que entreguen a su rey las dos terceras partes para la guerra. Por otros dos breves de 24 de Abril manda al obispo de Valencia que publique la cruzada, concediendo indulgencia plenaria en los dominios de Aragón, exceptuando las islas de Córcega y Cerdeña, a los que vayan a la guerra de Granada. Concede también a los clérigos de cualquier dignidad, canónigos, racioneros o curas que vengan a esta guerra, poder hacer suyos los frutos de sus prebendas durante su ausencia. $Y$ por último, concede la décima parte de todas las rentas eclesiásticas por tres años ${ }^{16}$.

Así las cosas, se inician los asedios de Almería y Algeciras por parte de Jaime II y de Fernando IV, respectivamente.

A lo largo de la empresa, Jaime II, al encontrarse falto de dinero para continuar, lo buscará en el país vecino y de nuevo en la curia pontificia.

Por una parte, escribe una carta a su cuñado, el rey Dionís de Portugal, pidiéndole un préstamo para la conquista de Almería, que iba por buen camino, a la vez que le envía otra a su hermana, la reina Isabel de Portugal, exponiéndole el negocio que trataba con su marido y pidiéndole su intervención: «Porque, Reyna vos rogamos muy carament que Vos rogades al dicho rey et guisedes con él que a esta sazón nos acorra de empréstamo et auremos a él et a vos para siempre que agradecer... ${ }^{17}$.

Por otra parte, envía de nuevo embajadores ante el Papa Clemente V, esta vez el militar Fortún Martín y Pedro Marsilio, de la orden de Predicadores y autor de la Cró-

13 MIQUEL ROSELL, F., Regesta de Letras Pontificias del Archivo de la Corona de Aragón. Sección Cancillería Real. Madrid, 1948. 330, p. 174.

14 SALAVERT Y ROCA, V., Cerdeña y la expansión mediterránea de la Corona de Aragón (12971314). II, p. 403.

15 Ibídem, II, p. 425.

16 TAPIA GARRIDO, J.A., Almería musulmana. Almería, 1978. II, p. 187.

17 Archivo de la Corona de Aragón. Registro General in Viagio Almeriae Jacobo Secundo. $1^{a}$ parte, fol. $27 \mathrm{~V}$. 
nica Latina de Jaime I, conocido por sus dotes políticas y diplomáticas. Pretendía Jaime II mejorar las concesiones que anteriormente habia hecho el Pontificado, ya que entre las peticiones de nuevos sobsidios, la más importante era conseguir la décima duplicada de las rentas de los bienes eclesiásticos para poder continuar la cruzada contra los moros de Almería, que ya se había iniciado.

Con fecha 6 de noviembre, Clemente V escribe desde el Priorato de Grosseau a Jaime II, dándole cuenta del resultado de las peticiones de sus nuncios y notificándole que habían sido desestimadas; la petición del subsidio de la Sede Apostólica para continuar la guerra de Granada por estar exhausto el erario de la Santa Sede con motivo de la reconquista de Ferrara y de los dispendios hechos en Tierra Santa y en Chipre; también fue rechazada la petición de la décima duplicada, por no haber sido concedida nunca por la Iglesia, ni en la cruzada contra Federico II de Sicilia ni tampoco en la recuperación del Cuerpo de San Luis del poder de los orientales. Sin embargo, concedía de nuevo las mismas indulgencias que para Tierra Santa al maestre y religiosos hospitalarios de Granada, la absolución de sus reinos de las censuras incurridas por comercio ilícito de víveres y armas con los sarracenos e indulgencia plenaria a quienes tomaran parte en la cruzada de Granada, personalmente o con subsidios $^{18}$.

Jaime II, que, pese a todo, concebía la empresa granadina como el camino más recto hacia Oriente, alimentaba la esperanza de dedicarse después a la recuperación de Tierra Santa, pues como dice Muntaner su objetivo era "acrecentar y multiplicar la santa fe católica»' ${ }^{19}$.

Pero la primera parte de su programa le salió mal. Habiendo abandonado Fernando IV el cerco de Algeciras en noviembre de 1309, Jaime II, para evitar una catástrofe, tuvo que levantar el sitio de Almería poco tiempo después. Muntaner, como hemos visto, considera que si el rey aragonés levantó el cerco fue porque se acercaba el invierno, porque los castellanos habián demostrado una gran deslealtad y porque los esclavos que le entregaron eran una ventaja más considerable que si hubiera tomado dos ciudades como Almería. El Padre Mariana quizás, más realista, dice que Jaime levantó el asedio por la poca esperanza de salir airoso de la empresa. Lo cierto es que el 26 de enero de 1310 Jaime II se retiraba de Almería con el consiguiente desprestigio.

El 15 de febrero, el rey envía al Papa desde Játiva una carta con su consejero Vital de Vilanova, que lleva el encargo de exponerle los motivos urgentes que le habían obligado contra su voluntad a levantar el asedio de Almería, para evitar que tuviera noticias deformadas de lo sucedido por otros conductos ${ }^{20}$, y para dejar una puerta abierta a la amistad y ayuda que ante cualquier nueva campaña pudiera necesitar del Pontífice.

18 MIQUEL ROSELL, F., Regesta de Letras Pontificias del Archivo de la Corona de Aragón. Sección Cancillería Real.Madrid, 1948. 352, p. 185.

19 MUNTANER, R., Crónica. Madrid, 1970. cap. 247, p. 509.

20 Archivo de la Corona de Aragón. Registro General in Viagio Almeriae Jacobo Secundo. $2^{\mathrm{a}}$ parte, fol. 237. 
Efectivamente, un año más tarde, el 16 de octubre de 1311, se inaugura el Concilio de Vienne y Jaime II envía sus embajadores con un programa bien concreto: «Cruzada sí, pero atacando a los sarracenos por todos los frentes, uno de los cuales, el más occidental, es Granada. Empecemos la conquista por la parte occidental y con la gracia de Dios podremos llegar a Tierra Santa» ${ }^{21}$.

Clemente $\mathrm{V}$, aunque alabó la buena disposición del monarca aragonés, contestó a los embajadores que sería mejor no mencionar a Granada, al tratar en el Concilio de los subsidios de Tierra Santa, puesto que franceses e ingleses estaban dispuestos a emprender la cruzada hacia Oriente. A través de esta entrevista conocieron la predisposición del Papa, que se hizo evidente en el Concilio, cuando anunció a la asamblea como una gran alegría, lo que para Aragón era una realidad triste: Felipe IV de Francia dirigiría los ejércitos cruzados hacia Tierra Santa ${ }^{22}$.

La campaña de Granada nuevamente volvía a perderse, esta vez en el Concilio de Vienne. Había que plantear, para poder salir adelante, una nueva estrategia.

\section{PEDRO MARSILIO ESCRIBE SU CRÓNICA}

Estando así las cosas, comienza Pedro Marsilio a traducir el Llibre dels Feyts. Pero ¿qué interés podría tener Pedro Marsilio en traducir las gestas de un rey muerto que ya circulaban en romance? Se han barajado un sinfín de motivaciones, entre las que se cuentan la de halagar al monarca aragonés regalándole el libro de las gestas de su abuelo o la de ensalzar a la Orden de Predicadores, puesto que introduce fragmentos dedicados a ella que en la Crónica catalana no existen ${ }^{23}$. Conociendo el talante de Pedro Marsilio y su categoría intelectual, no cabe duda que contaba con elementos suficientes para llevar a cabo otro tipo de obra, en la que se plasmara mejor su capacidad creadora. Todo ello induce a pensar que su objetivo no estaba en la redacción de la Crónica sino, más bien, en su traducción.

Traducir un texto supone, ahora y siempre, darlo a conocer a un público que desconoce la lengua original del mismo. Probablemente lo que Marsilio pretendía era poner la Crónica de Jaime I en manos de un sector no conocedor del catalán, es decir, ampliar el área de lectura de la Crónica catalana, universalizarla y posiblemente hacerla llegar al mundo eclesiástico y, concretamente, a la curia romana y al Papa. Pedro Marsilio, que conoció personalmente a Clemente V, captaría, sin duda, que al Pontífice le resultaba complicado el catalán. En un carta que Bernardo de Fenollar dirigió a Jaime II aparece explicitado que el Papa «entenía be nostre romanc mas nol sabría legir, mas que tantost lo tornassem en latí que molt volenters lo legiría e hi estudiaría» ${ }^{24}$.

Por otra parte, en varios pasajes de la Crónica latina aparecen fragmentos como

21 FINKE, H., Acta Aragonensia. Berlín und Leipzig, 1908. II, pp. 234-237.

22 MARTÍNEZ SAN PEDRO, Mª.D., Crónica Latina de Jaime I. Almería, 1984, p. 44.

23 Ibídem, pp. 29-33.

24 SALAVERT Y ROCA, V., Cerdeña y la expansión mediterránea de la Corona de Aragón (12971314). II, p. 425. 
«... et certe movere vos debet hoc principaliter honor Dei et cristiane fidei promotio» 25 , 0 «... prima ratio es fide» ${ }^{26}$, o también «... petimus necessarium subsidium $»^{27}$, que no existen en el texto catalán y que manifiestan con toda claridad que Marsilio quiso introducir intencionadamente, de un lado la idea de Cruzada y la lucha por la fe y de otro la petición de subsidios y ayudas económicas, todo ello en boca de Jaime $\mathrm{l}$.

Así pues, no parece extraño pensar que Marsilo, estableciendo un paralelismo entre lo que fue y lo que hizo Jaime I, con lo que podría ser y hacer Jaime II, pretendiera atraerse la atención del Pontífice, como ya lo había hecho Ramón Lull con su obra «De acquisitione Terrae Sanctae»28. De esta forma se intentaba desviar la atención de Clemente V, muy centrada en la recuperación de los Santos lugares desde la celebración del Concilio de Vienne, hacia la península y, más concretamente, hacia el Reino de Granada, donde el problema musulmán seguía siendo preocupante y si no se resolvía, no era tanto por falta de estrategas o de planes de ataque eficientes cuanto por falta de fondos económicos.

25 MARTíNEZ SAN PEDRO, Ma.D., Crónica Latina de Jaime I. Almería, 1984, p. 159.

26 Ibídem, p. 194.

27 Ibídem, p. 161.

28 GOÑl GAZTAMBIDE, J., Historia de la Bula de la Cruzada en España. Vitoria, 1958, p. 258. 